\title{
Supported Reagents: Opportunities and Limitations
}

\author{
Gurdip Bhalay,* Andrew Dunstan, Angela Glen \\ Novartis Horsham Research Centre, Wimblehurst Road, Horsham, West Sussex, RH12 5AB, UK \\ Fax +44 1403 323307; E-mail: gurdip.bhalay@pharma.novartis.com \\ Received 31 August 2000
}

new tonls

\begin{abstract}
The in vitro testing of collections of compounds has reached a stage where more compounds can be tested than can be synthesised. To keep up with this demand chemists have turned towards investigating parallel synthesis methods, which reduce the time spent in the work-up of a reaction. The vast literature regarding solution-phase chemistry and simple reaction monitoring has encouraged chemists to consider synthesis in solution-phase with the aid of supported reagents. Although the first developments were published over three decades ago, only recently has their appeal reached a wider audience.

\author{
Introduction \\ Oxidations using supported reagents \\ Reductions using supported reagents \\ Supported triphenylphosphine \\ Supported nucleophiles \\ Supported bases \\ Supported coupling reagents \\ Supported catalysts \\ Multi-step synthesis using supported reagents \\ Conclusions and outlook
}

Key words: catalysis, combinatorial chemistry, natural products, oxidations, reductions

\section{$1 \quad$ Introduction}

For the synthetic organic chemist supported reagents can reduce the time spent in handling reagents and in the work up of the target compound by reducing or eliminating the need for labour intensive purification steps. Supported reagents make it possible to use filtration to remove some or all of the reactants from the products. This has been the main stimulus for the recent growth in interest of supported reagents. Medicinal chemists have begun to evaluate their use for the parallel synthesis of compound libraries. For the pharmaceutical companies, the discovery of an efficacious compound is of paramount interest; the potential revenue promised by a market leading drug is enormous thus medicinal chemists are experiencing ever increasing pressures to find new drugs. This has been a major factor which has been marked with the rise of combinatorial chemistry ${ }^{1}$ and solid-phase synthesis. But chemistry on the solid-phase, although successful in many cases is limited by two principle factors, firstly by the number of known validated protocols. As often solution-phase chemistry requires some customisation before it proceeds well on the solid-phase. Secondly the linker, the point of attachment of organic molecules to the solid-phase requires a functional group handle; very often a polar func- tional group remains to serve as a memory of the attachment point in the final compounds; this restricts the structural content of the library and hence the diversity of the compound collection.

Working in solution-phase counters these restrictions and allows for easier reaction monitoring, for example by thin layer chromatography. Supported reagents offer an opportunity to hasten solution-phase synthesis by combining the advantages of solid-phase and solution-phase chemistries.

The major opportunities which supported reagents offer are:

(i) ease of workup.

(ii) make safe toxic, odorous or explosive reagents.

(iii) combinations of supported reagents can be added without interaction between them.

The main limitations are:

(i) reactions are often slower than their homogeneous analogues.

(ii) the support needs to be compatible with the reaction conditions.

(iii) reagents can be expensive to prepare and the loading can be low - limiting the scale of an experiment.

This review will attempt to highlight the synthetic utility of supported reagents. It is beyond the scope of this article to cover every published report, rather to highlight those reagents which in our opinion the synthetic organic chemist should be made aware of. We have also omitted the topic of scavenger resins ${ }^{2}$ the inspired reader is directed towards recent review articles ${ }^{3}$ which cover the subject in greater detail. The term polymer supported reagent (PS-R) will be used for those reagents which have been attached to cross linked polystyrene. The reagent may be either covalently or ionically attached to the organic support as illustrated (Scheme 1) by PS-triphenylphosphine 1 and PSborohydride exchange resin 2 respectively. Alternatively the reagent may be covalently attached to a polyethylene glycol, to provide the PEG-supported reagents $\mathbf{3 b}$. In the final classification, the reagent may be adsorbed on to an inorganic solid such as silica to give what we shall call the solid supported reagent (SS-R) 4. 


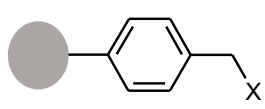

for example $\mathrm{X}=\mathrm{PPh}_{2}$

1 PS-Triphenylphosphine<smiles></smiles>

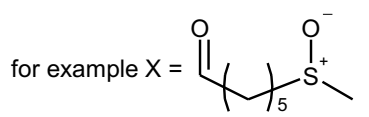

3b PEG-Sulfoxide

Scheme 1

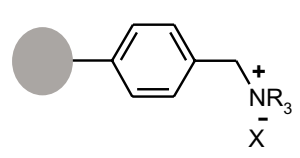

for example $\mathrm{X}=\mathrm{BH}_{4}$ $\mathrm{R}=\mathrm{CH}_{3}$

2 PS-Borohydride

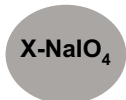

for example $X=$ Silica

4 SS-Sodium periodate

\section{Oxidations using supported reagents}

\subsection{PS-Sulfoxide and PEG-sulfoxide}

The Swern oxidation method ${ }^{4}$ is widely used to oxidise alcohols to aldehydes and ketones. The major byproduct is dimethyl sulfide - a toxic and unpleasant smelling gas. Cross-linked chloromethyl polystyrene (Merrifield resin) has been used to support 6-methanesulfinyl hexanoic acid to give the PS-sulfoxide ${ }^{5} \mathbf{3 a}$ and substituted for dimethyl sulfoxide in the oxidation procedure. Using this PS-reagent 3a the oxidation reactions (Scheme 2) occurred under normal Swern conditions showing PS-sulfoxide 3a to be an efficacious dimethyl sulfoxide substitute. A variety of alcohols have been used $(\mathbf{5 , 7 , 9 )}$ and the products $(\mathbf{6}, \mathbf{8}, \mathbf{1 0})$ obtained in excellent yields $(94 \%, 93 \%$ and $90 \%$ respectively). After oxidation the sulfide byproduct, now support bound, was easily separated from the product without the aforementioned hazards. The polymer

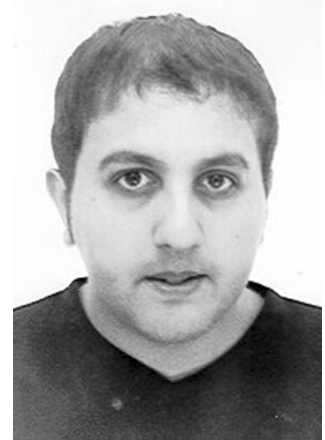

Gurdip Bhalay was born in Derby, England in 1968. He received a $\mathrm{BSc}$ in chemistry from The University of Nottingham in 1989 and remained there to complete his $\mathrm{Ph} . \mathrm{D}$ in organic chemistry under the supervision of Professor Raymond C. F. Jones. After which he moved to a
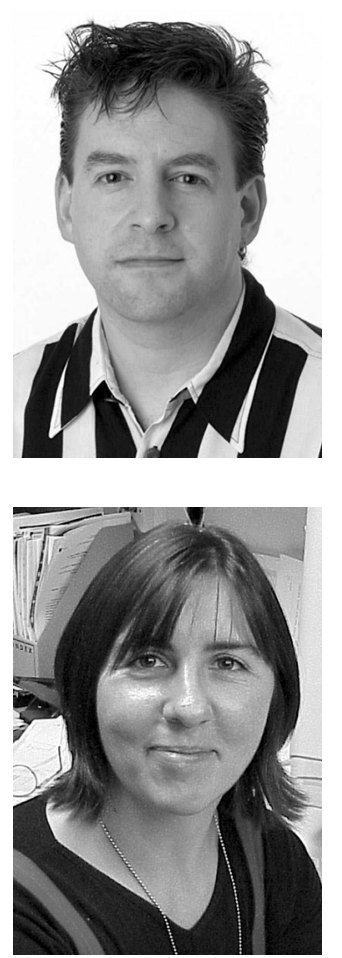

Angela Glen was born in South Shields, England in 1970 and studied at the University of Manchester Institute of Science and Technology (UMIST) gaining a BSc in chemistry in 1992. She then moved to post-doctoral position at Oxford University, working with Professor Stephen. G. Davies. He then joined the newly formed Oxford Diversity in 1995 as one of the first chemists to be employed in the combinatorial chemistry start-up and remained there until 1997. He subsequently

wall and worked for the Maybridge Chemical Company. In 1990 he moved to the Sandoz Institute of Medical Research working on novel analgesics and trans- joined Novartis in Horsham for whom he currently works as a Laboratory Head of Medicinal Chemistry within the respiratory disease therapeutic area.

ferred over to the Novartis Horsham Research Centre in 1997, where he works as a Research Associate within the respiratory disease therapeutic area.
Kings College, London University as a Research Associate working on peptide synthesis using solid-phase chemistry. In 1996 she joined the Sandoz Institute of Medical Research working on novel analgesics and transferred over to the Novartis Horsham Research Centre in 1998, where she works as a Research Associate within the respiratory disease therapeutic area. 
supported sulfide could be recycled and reused after oxidation with sodium periodate. However the oxidation capacity of the polymer supported reagent was reduced from $92 \%$ to $78 \%$. The authors suggest degradation of the polymer support to be the likely cause. In a later publication ${ }^{6}$ the same laboratory reported that attachment of the same sulfoxide to a soluble polyethylene glycol polymer overrides these limitations and the PEG-sulfoxide $\mathbf{3 b}$ could be recycled numerous times without apparent loss of activity. The PEG-sulfoxide $\mathbf{3 b}$ was removed by precipitation using diethyl ether followed by filtration.

\subsubsection{PS-Carbodiimide}

When dealing with acid sensitive compounds the Moffatt oxidation ${ }^{7}$ procedure has proven to be an extremely valuable method. Under the classical conditions dicyclohexylcarbodiimide is used, and the major contaminant is the corresponding urea which can be difficult to remove from the product. Although water soluble carbodiimides have partially addressed this problem the isolation of water soluble aldehydes or ketones can cause some difficulties. In this regard the polymer supported version $11^{8}$ offers an instant advantage. Reactions can be carried out in benzene dimethyl sulfoxide mixtures or in neat dimethyl sulfoxide, with the latter requiring longer reaction times. The labile prostaglandin intermediate (Scheme 3) 12 was readily converted to the aldehyde $\mathbf{1 3}$ in high yield (91\%). If desired the polymer bound urea can be transformed back to the carbodiimide by dehydration of the urea using $p$-toluenesulfonyl chloride and triethylamine in dichloromethane at reflux. The recycled resin displays a small loss in activity.

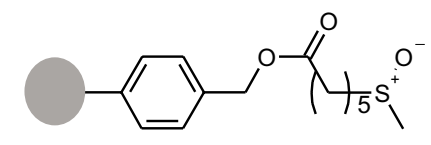

$3 a$<smiles>COc1cc(CO)cc(OC)c1</smiles>

5<smiles>OC/C=C/c1ccccc1</smiles>

7

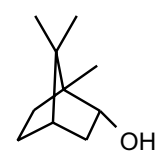

9<smiles>COc1cc(C=O)cc(OC)c1</smiles>

6

$94 \%$<smiles>O=C/C=C/c1ccccc1</smiles>

8 $93 \%$ $\underset{\text { DCM, Et }{ }_{3} \mathrm{~N},-50^{\circ} \mathrm{C}}{\stackrel{3 a}{\text { to R.T., overnight }}}$ $\mathrm{DCM}, \mathrm{Et}_{3} \mathrm{~N},-50^{\circ} \mathrm{C}$ to R.T., overnight

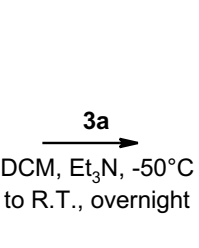

Scheme 2
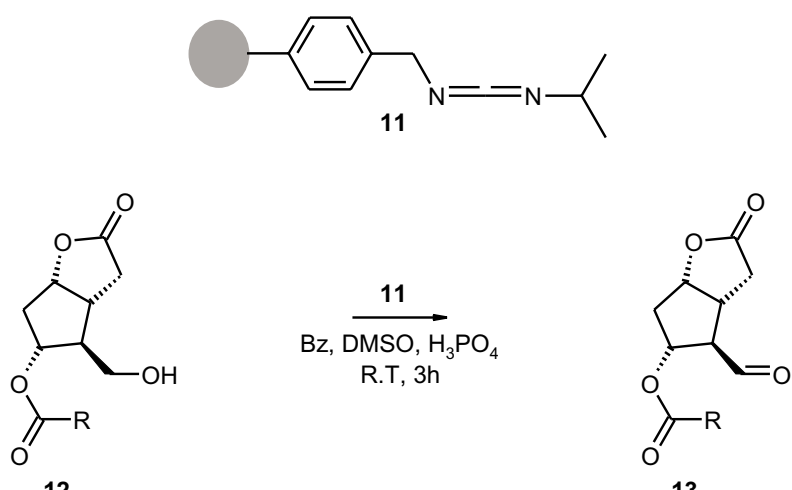

13

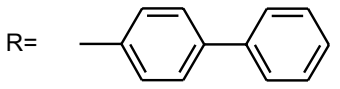

$91 \%$

Scheme 3

\subsubsection{PS-Perruthenate}

Oxidations using PS-perruthenate ${ }^{9}$ (PS-P) reagent 14 have been carried out using either stoichiometric or catalytic amounts of the reagent. The catalytic system $(20 \mathrm{~mol} \%$ of PS-P) operates in conjunction with a co-oxidant such as trimethylamine $N$-oxide (TMO) which produces the volatile trimethylamine as the by-product and leaves the desired carbonyl compound free from any other contamination. Typically reactions (Scheme 4) were carried out in dichloromethane at room temperature using either trimethylamine $\mathrm{N}$-oxide (TMO) or $\mathrm{N}$ methylmorpholine $\mathrm{N}$-oxide (NMO). Molecular sieves

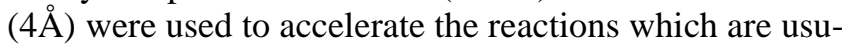
ally complete in $16 \mathrm{~h}$ giving good to excellent yields of the products $(>50 \%)$. This 'clean technology' has been extended to the use of oxygen ${ }^{10}$ as the co-oxidant to once
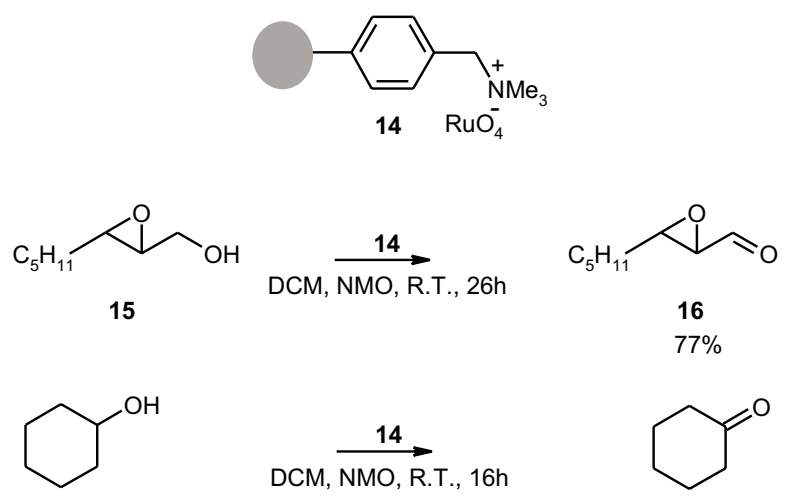

17

18<smiles>CCN(O)CC</smiles><smiles>[R20][N+](=CC)CCC</smiles>

$20 \mathrm{a}\left(\mathrm{R}=\mathrm{CO}_{2} \mathrm{CH}_{3}\right)$

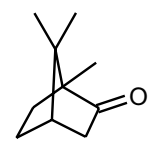

10 $90 \%$
Scheme 4 
again provide the products free from impurities. PS-P 14 has also been used to generate nitrones from secondary hydroxylamines. ${ }^{11}$ Diethylhydroxylamine 19 was converted to the nitrone $\mathbf{2 2}$ in chloroform at room temperature in a one-pot procedure. When generated in the presence of a dipolarophile such as methyl acrylate 20a $\left(\mathrm{R}=\mathrm{CO}_{2} \mathrm{CH}_{3}\right)$ the isoxazolidine $\mathbf{2 0 b}$ was produced in high yield $(91 \%)$ via a 1,3-dipolar cycloaddition.

\subsubsection{PS-hypervalent iodine (PS-DIB)}

The synthesis and use of polymer supported (diacetoxyiodo)benzene (PS-DIB) $\mathbf{2 3}$ has been known for some years ${ }^{12}$ but recently its synthetic application has been extended. ${ }^{13}$ The reagent has been used to obtain a range of useful products (Scheme 5) in oxidative reactions which proceed in high yield and high purity. Acetophenones such as $\mathbf{2 4}$ were $\alpha$-hydroxylated using heat $\left(60^{\circ} \mathrm{C}\right)$ or excess $\mathbf{2 3}$ at room temperature to give acyloins resembling 25 quantitatively. Similarly, benzyl alcohols were oxidised to the benzaldehydes (100\%). Worthy of a special mention is an oxidative diastereoselective spirocyclisation reaction using tyrosine derivatives $\mathbf{2 6}$ which gave the chiral spirodienones $\mathbf{2 7}, \mathbf{2 8}$ and $\mathbf{2 9}$ (84\%, 80\%, 84\% respectively). Furthermore the use of an excess of the PSDIB 23 gave consistently high yields of the desired products, in contrast to the soluble material which can be capricious. The PS-DIB $\mathbf{2 3}$ consumed in these reactions was regenerated by oxidation with peracetic acid. The regenerated resin showed no loss in activity.

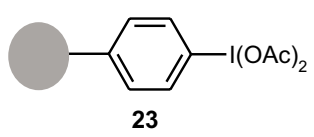<smiles>CC(=O)c1ccc(Cl)cc1</smiles>

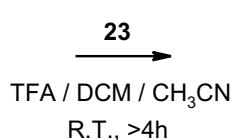

24 R.T., $>4 \mathrm{~h}$<smiles>[R]C(Cc1ccc(O)cc1)C(=O)O</smiles>

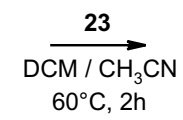

26

$27 \mathrm{R}=\mathrm{H}, 84 \%$

$28 \mathrm{R}=\mathrm{NHBoc}, 80 \%$ $29 \mathrm{R}=\mathrm{NHFmoc}, 84 \%$

Scheme 5

\subsubsection{PS-Osmium tetroxide}

The cis-dihydroxylation of alkenes by osmium tetroxide to form cis-1,2-diols is one of the most reliable synthetic transformations known. ${ }^{14}$ The hazardous toxicity associated with osmium tetroxide and high cost have led to the development of non volatile tertiary amine - osmium tetroxide adducts which still retain the original reactivity of the reagent. Catalytic systems were developed at a later stage using catalytic amounts of osmium tetroxide working together with a stoichiometric amount of secondary oxidant to regenerate the tetroxide. The polymer bound reagents ${ }^{15}$ 30, 31 (Scheme 6) were easily prepared from cross-linked poly 4-vinylpyridine or by using a resin bound 1,4-diazabicyclo[2.2.2] octane (DABCO) equivalent. These resins bearing a tertiary amino function were then treated with a solution of osmium tetroxide in cyclohexane to complex the tetroxide to the resin via the amino function. PS-Osmium tetroxide offers the advantage of an easy workup without the need to decompose residual osmium tetroxide. The hydroxylations of olefins such as $\mathbf{3 2}$, 34, and $\mathbf{3 6}$ demonstrate this and reactions were carried out in tert-butyl alcohol with $0.2-1 \%$ of PS-osmium tetroxide using hydrogen peroxide or trimethylamine $\mathrm{N}$-oxide (TMO) co-oxidant. The best results, with respect to reaction rate and yield were obtained by using either $\mathbf{3 0}$ or $\mathbf{3 1}$ with trimethylamine $N$-oxide (TMO) in tert-butyl alcohol. Iodometric testing confirmed that no leaching of the osmium tetroxide into the product occurred. Once made the PS-Osmium tetroxide can be stored for weeks without any noticeable decline in reactivity.

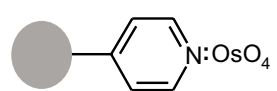

30

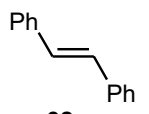

32<smiles>CCOC/C=C\C(=O)OCC</smiles>

34

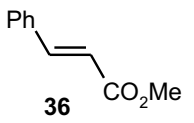

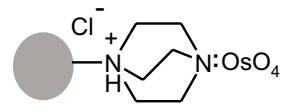

31
Scheme 6

Kobayashi has shown that polystyrene can be used to microencapsulate ${ }^{16}$ (MC) osmium tetroxide. The osmium tetroxide becomes physically enveloped by the polymer presumably on the basis of interactions between the $\pi$ electrons of the benzene rings of the polymer and a vacant orbital of osmium tetroxide. Prepared by simply cooling a solution of polystyrene and osmium tetroxide from $40^{\circ} \mathrm{C}$ to $0{ }^{\circ} \mathrm{C}$, followed by washing to remove unencapsulated reagent. The effective use of PS-MC-osmium tetroxide 
was demonstrated by dihydroxylating a range of olefins using 5mol\% of PS-MC-osmium tetroxide and $N$-methylmorpholine $N$-oxide (NMO) in a water-acetone-acetonitrile $(1: 1: 1 \mathrm{v} / \mathrm{v} / \mathrm{v})$ solvent mixture at room temperature over 6-48h. In each case the product diol was obtained in a high yield $(>74 \%)$ and gratifyingly without any detectable leaching of osmium tetroxide.

\subsubsection{SS-Sodium periodate}

Sodium periodate is used for the oxidative cleavage of vicinal diols into dicarbonyl compounds. Its specificity and reactivity under mild, neutral conditions have made it a popular reagent amongst carbohydrate chemists. The reactions are usually performed in aqueous alcohols or tetrahydrofuran, but the effectiveness is limited by its insolubility in non-polar solvents. This can pose problems for vicinal diols which are either poorly soluble in aqueous alcoholic media or for those product aldehydes which are very water soluble and thus difficult to extract from water. Silica gel supported sodium periodate ${ }^{17} 4$ (Scheme 1) has been used to overcome these difficulties. The reagent was prepared by adding a hot $\left(70^{\circ} \mathrm{C}\right)$ solution of sodium periodate $(2.6 \mathrm{~g}$ in $5 \mathrm{ml}$ of water) to silica gel $(10 \mathrm{~g}$, 230-400 mesh). Reactions (Scheme 7) have been performed in dichloromethane at room temperature in short reaction times $(10-30$ mins $)$. Each of the diols 38, 40 and 42 gave good yields of the expected products (all $>90 \%$ ).<smiles>OC1CCCCC1O</smiles>

38

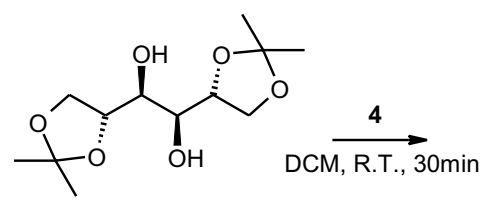

40<smiles>CC1(C)[C@H]2C[C@@](C)(O)[C@@H](O)C[C@H]21</smiles>

42
Scheme 7

$$
\underset{\text { DCM, R.T., } 15 \mathrm{~min}}{\stackrel{4}{\longrightarrow}}
$$<smiles>O=CCCCCC=O</smiles>

\section{9}

$98 \%$

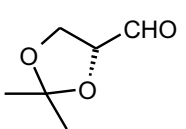

41

$95 \%$
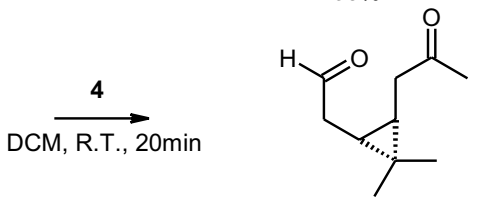

43

3

\section{Reductions using supported reagents}

\subsection{PS-Borohydride exchange resin}

Amberlyst anion exchange resins of the quaternary ammonium type have been used to support borohydride anion to give what is now generally called polymer supported borohydride exchange $\operatorname{resin}^{18}$ (PS-BER) 2; a polymer supported equivalent of sodium borohydride.

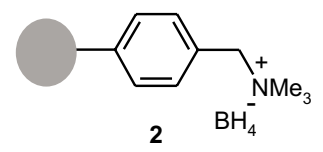<smiles>O=Cc1ccccc1</smiles>

44<smiles>O=CCCCCCC=O</smiles>

44<smiles>O=C/C=C/c1ccccc1</smiles>

50<smiles>CC(=O)/C=C/c1ccccc1</smiles>

52<smiles>O=[N+]([O-])C1=CCCCC1</smiles>

54<smiles>Nc1ccccc1</smiles>

56

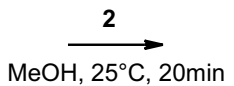<smiles>CO[C@H](C)Cc1ccccc1</smiles><smiles></smiles>

46 $98.5 \% \quad 6.5 \%$<smiles>OC/C=C/c1ccccc1</smiles>

51

$99 \%$

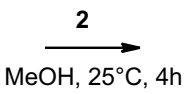<smiles>C[C@@H](O)/C=C/c1ccccc1</smiles>
53 $90 \%$<smiles>O=[N+]([O-])C1CCCCC1</smiles>

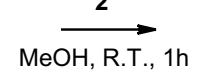<smiles>Nc1ccccc1</smiles>

57 $96 \%$
Scheme 8

The reagent was prepared by stirring an aqueous solution of sodium borohydride with the Amberlyst resin (chloride form) for 30 minutes. After filtering and washing with distilled water to remove excess sodium borohydride, the resin was dried under vacuum to give the product ready to use. Its reducing capacity was determined by reaction with benzaldehyde and glc analysis of the resulting benzyl alcohol. A series of competitive reduction experiments established that using 2 the reduction of aldehydes occurs faster than ketones (Scheme 8). Treating a mixture of benzaldehyde 44 and acetophenone 45 with PS-BER 2 produced the alcohol 46 almost exclusively (99\%). Aromatic aldehydes like $\mathbf{4 4}$ are preferentially reduced in the presence of aliphatic aldehydes $\mathbf{4 8}$ albeit at a lower temperature $\left(-10^{\circ} \mathrm{C}\right)$. These kinetic differences can be exploited to chemoselectively reduce one carbonyl group in the presence of the other. Also the $\alpha, \beta$-unsaturated aldehyde $\mathbf{5 0}$ or ketone $\mathbf{5 2}$ was reduced to the alcohols $\mathbf{5 1}$ and $\mathbf{5 3}$ at room 
temperature without reduction of the conjugated double bond, thus demonstrating an alternative to the solution phase systems developed by Luche. For strong Michael acceptors such as 1-nitro-1-cyclohexene 54, hydride transfer is observed to occur in a conjugate sense to furnish the saturated nitro compound $\mathbf{5 5}$ in good yield (80\%). Finally using PS-BER 2 azidomethylbenzene 56 was reduced to the aniline $\mathbf{5 7}(96 \%)$ in refluxing methanol in $3 \mathrm{~h}$.

\subsubsection{PS-Cyanoborohydride}

Prepared in a similar way to PS-BER, PScyanoborohydride ${ }^{19}$ has been used to mediate reductive amination reactions at room temperature. The reactions are slower when compared with the parent reaction using sodium cyanoborohydride but proceed in equally high yields. The easy work-up together with the retention of cyanide ion on resin make PS-cyanoborohydride a safe and effective alternative to classical methodology.

\subsubsection{PS-Borohydride exchange resin and nickel acetate}

The addition of transition metal salts to sodium borohydride is known to enhance the reducing ability of sodium borohydride when compared with the reducing agent alone. The same holds true for a combination of PS-BER $\mathbf{2}$ and nickel acetate. ${ }^{20}$ Both aliphatic and aromatic nitro compounds can be reduced in short reaction times and in good yields. A wide range of substrate functionality is compatible with this reagent combination (Scheme 9) and it has been described as the reagent of choice for the reduction of nitro group to the amino group as seen by compounds 58, 60, 62. This combination also serves to reduce aromatic aldoximes $\mathbf{6 4}$ and azides $\mathbf{6 6}$ to the corresponding amines 65 and 67. A variety of aromatic chlorides, bromides and iodides have also been reduced to give the dehalogenated product, as exemplified by reduction of 3bromoquinoline $\mathbf{6 8}$ into quinoline $\mathbf{6 9}$ at room temperature in $3 \mathrm{~h}(80 \%)$.

\subsubsection{PS-Tin hydride and PS-tin chloride}

The versatility of tin hydride reagents and the associated difficulties in separating this toxic metal from the product has led to the development of a PS-tin hydride $\mathbf{7 0}$ equivalent. The most recent preparation of this has been described by Nicolaou ${ }^{21}$ using an adapted but previously reported hydrostannation protocol. ${ }^{22}$ This gives a reagent where the tin atom is separated from the aromatic nucleus by two atoms, hence is stable towards splitoff. These reagents have been developed and $\mathrm{used}^{23}$ (Scheme 10) to mediate numerous radical reactions, typically in dry benzene or toluene at elevated temperatures for $4 \mathrm{~h}$ using the radical initiator 2,2'-azobis(isobutyronitrile). Examples include: the dehalogenation of the $\alpha$-bromo camphor derivative $\mathbf{7 2}$ and deamination of secondary and tertiary<smiles>O=C(O)c1ccccc1[N+](=O)[O-]</smiles>

58<smiles>CC(=O)c1ccc([N+](=O)[O-])cc1</smiles>

60<smiles>O=[N+]([O-])C1CCCCC1</smiles>

62<smiles>ON=Cc1ccco1</smiles>

64<smiles>CCOC(=O)CN</smiles>

66<smiles>Brc1cnc2ccccc2c1</smiles>

68

$$
\underset{\mathrm{MeOH}, 0^{\circ} \mathrm{C}, 1 \mathrm{~h}}{\stackrel{\mathrm{Ni}(\mathrm{OAc})_{2}}{ }}
$$<smiles>Nc1ccccc1C(=O)O</smiles>

59 $78 \%$ $\mathrm{MeOH}, 0^{\circ} \mathrm{C}, 1 \mathrm{~h}$<smiles>CC(=O)c1ccc(N)cc1</smiles>

61 $96 \%$<smiles>NC1CCCCC1</smiles>

63 $94 \%$
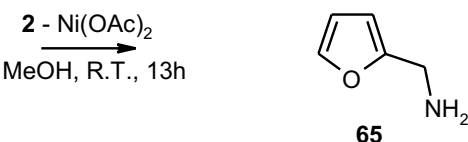

$81 \%$

$\underset{\mathrm{MeOH}, \mathrm{R.T} .,}{\stackrel{\mathrm{Ni}(\mathrm{OAc})_{2}}{\longrightarrow}} 30 \mathrm{~min}$<smiles>CCOC(=O)CN</smiles>

67

$93 \%$

$$
\underset{\mathrm{MeOH}, \mathrm{R.T} .,}{\stackrel{-\mathrm{Ni}(\mathrm{OAc})_{2}}{\longrightarrow}}
$$

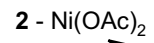

Scheme 9

amines. For example cyclohexylamine $\mathbf{7 4}$ is converted to cyclohexane via the isocyanide $\mathbf{7 5}$ in moderate yield (44\%). PS-Tin hydride 70 was also effective in mediating a Barton dehydroxylation of a steroid alcohol (80\%).

PS-Tin chloride, the synthetic precursor to PS-tin hydride, has been used as a linker in the solid-phase synthesis of the natural product $(S)$-Zearalone ${ }^{21}$ (Scheme 10). Although this is beyond the scope of this article, we think this minor digression will interest the reader. In this synthesis, PS-tin chloride reacts with the vinyl lithium $\mathbf{7 7}$ in tetrahydrofuran to give, after removal of the tertbutyldimethylsilane (TBS) protecting group, a resin bound (E)-6-(dibutylphenethylstannanyl)hex-5-en-1-ol analogue 78 in high yield (91\% over two steps). This fragment was elaborated to give $\mathbf{7 9}$ and the synthesis concluded using a Stille coupling to deliver the natural product $\mathbf{8 0}$. 


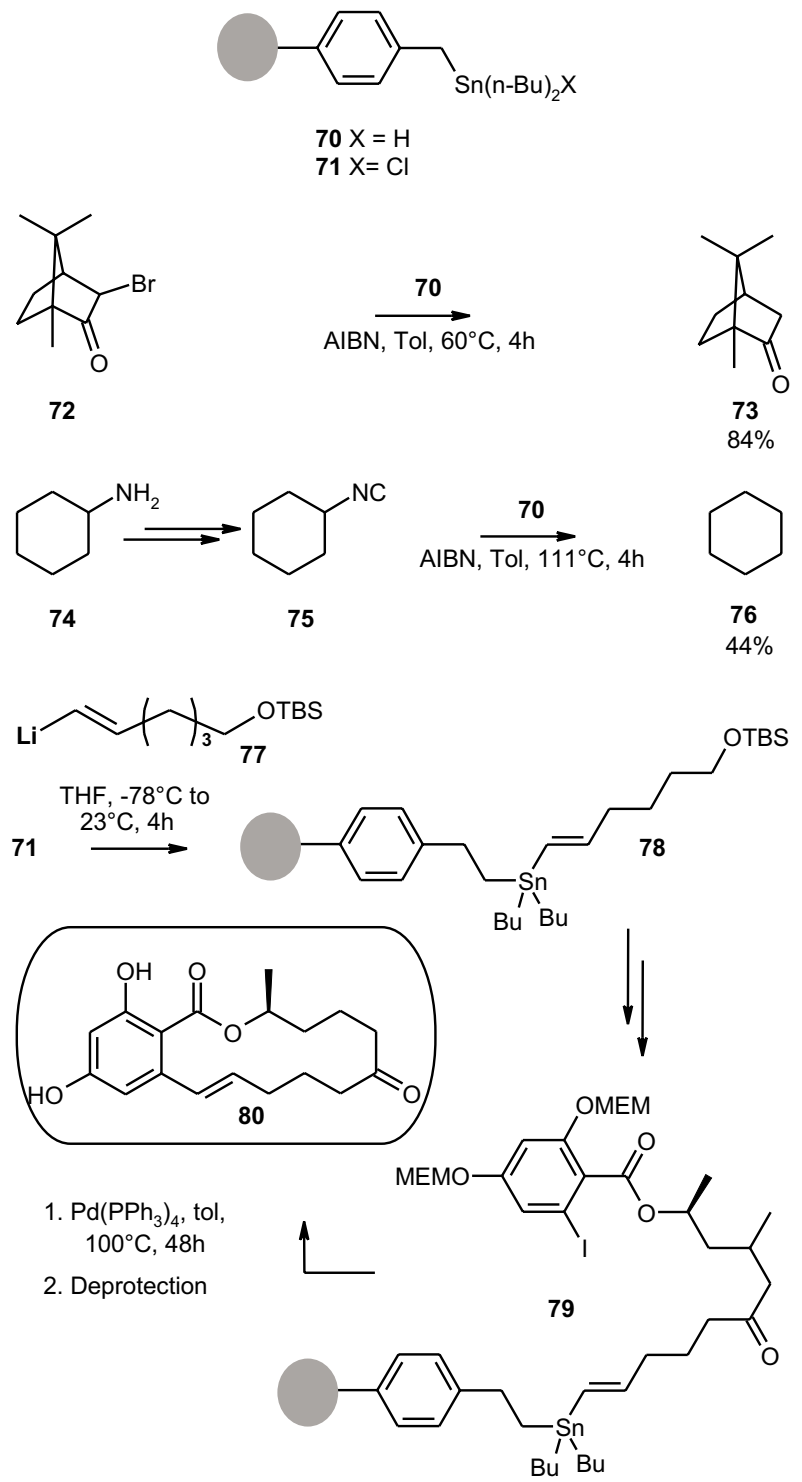

Scheme 10

\section{$4 \quad$ Supported triphenylphosphine}

Many reactions which involve the use of triphenylphosphine produce triphenylphosphine oxide as a common byproduct. This can cause problems in its removal from the product as it is neither water soluble nor volatile. So PStriphenylphosphine ${ }^{24} \mathbf{1}$ introduces an instant advantage.

PS-triphenylphosphine $\mathbf{1}$ and carbon tetrachloride have been used to convert both carboxylic acids to the corresponding acid chlorides (Scheme 11) and alcohols to the corresponding alkyl chlorides. The reactions ${ }^{25}$ give good yields under mild and neutral conditions with short reaction times under reflux $(<6 \mathrm{~h})$. Using these conditions the trans-cinnamic acid $\mathbf{8 4}$ and phenoxyacetic acid were transformed to their acid chlorides $\mathbf{8 5}$ and $\mathbf{8 7}(77 \%$ and $50 \%$ respectively). This reagent combination has also been used to prepare amides ${ }^{26}$ from $N$-protected amino ac-<smiles>[Y2](c1ccccc1)c1ccc(C2CCCCC2)cc1</smiles>

$81 \mathrm{X}_{2}=\mathrm{Cl}_{2}$

$82 \mathrm{X}_{2}=\mathrm{Br}_{2}$

$83 \mathrm{X}_{2}=\mathrm{I}_{2}$<smiles>O=C(O)/C=C/c1ccccc1</smiles>

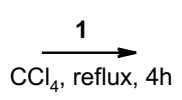<smiles>O=C(Cl)/C=C/c1ccccc1</smiles><smiles>O=C(O)C[18O]c1ccccc1</smiles><smiles>O=C(Cl)[C+](Oc1ccccc1)[18O]c1ccccc1</smiles><smiles>NC(=O)c1ccc([N+](=O)[O-])cc1</smiles><smiles>N#Cc1ccc([18OH])cc1</smiles><smiles>O=C(Nc1ccccc1)c1ccccc1</smiles>

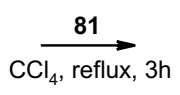<smiles>ClC(=Nc1ccccc1)c1ccccc1</smiles><smiles>ON=C(c1ccccc1)c1ccccc1</smiles>

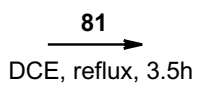<smiles>ClC(=Nc1ccccc1)c1ccccc1</smiles>

$88 \%$<smiles>O/N=C/c1ccccc1</smiles><smiles>CNC(=O)Nc1ccccc1</smiles>

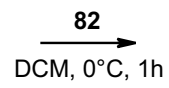<smiles>[R]C(CO)NC(=O)O</smiles>

98

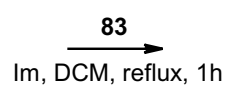<smiles>[R]C(CI)NC(=O)O</smiles>

$99 \mathrm{R}=\mathrm{Me}(90 \%)$ $100 \mathrm{R}=\mathrm{Bn}(92 \%)$
Scheme 11

ids and amines. The three major amine protecting groups ( $\mathrm{CBz}$, Boc and Fmoc) were shown to be compatible with the conditions and the required amides were isolated in $78-100 \%$ yield, with negligible epimerisation at the $\alpha$-carbon atom.

Another application has found these reagents to be an effective combination ${ }^{27}$ for the dehydration of primary amides such as 4-nitrobenzamide $\mathbf{8 8}$ and aldoximes like benzaldehyde oxime $\mathbf{9 4}$ to the corresponding nitriles $\mathbf{8 9}$ and 95. Reactions were carried out in carbon tetrachloride or 1,2-dichloroethane at reflux $(<4 \mathrm{~h})$ and afforded the products in good to excellent yields $(>75 \%)$. Under the same conditions secondary amides such as $N$-phenylben- 
zamide $\mathbf{9 0}$ and the ketoxime diphenylmethanone oxime 92 react to give the imidoyl chloride $\mathbf{9 3}$. The products were produced in essentially quantitative yields. This is probably due to the simplified workup of these sensitive intermediates.

\subsection{PS-Triphenylphosphine dichloride $\left(\mathbf{P S}-\mathrm{PPh}_{3} \mathrm{Cl}_{2}\right)$}

Reaction of PS-phosphine oxide with phosgene in dichloromethane at $25^{\circ} \mathrm{C}$ produces the corresponding PS-triphenylphosphine dichloride ${ }^{28} \mathbf{8 1}$, which has been used to effect each of the transformations already outlined (Section 4). The spent resin was regenerated using phosgene to give the reagent ready for re-use.

\subsubsection{PS-Triphenylphosphine dibromide $\left(\mathrm{PS}-\mathrm{PPh}_{3} \mathrm{Br}_{2}\right)$}

PS-Triphenylphoshine dibromide 82 (Scheme 11) is effortlessly prepared by the addition of bromine to PS-triphenylphosphine $\mathbf{1}$ and has been used to synthesise carbodiimides ${ }^{29}$ from $N, N^{\prime}$-disubstituted ureas. Carbodiimides like $\mathbf{9 7}$ are synthetically useful intermediates and have been used towards the synthesis of guanidines and several heterocyclic systems. Carbodiimide synthesis is hampered by their instability and intolerance towards the commonly used purification techniques such as distillation and chromatography. Using PS-triphenylphoshine dibromide 82, a good yield (90\%) of the carbodiimide $\mathbf{9 7}$ was obtained by slowly adding the urea 96 to a mixture of PS-triphenylphosphine dibromide $\mathbf{8 2}$ and triethylamine in cold dichloromethane $\left(0^{\circ} \mathrm{C}\right)$. In an earlier publication $N, N^{\prime}$-thioureas were used to the same overall effect. ${ }^{30}$

\subsubsection{PS-Triphenylphosphine diiodide (PS- $\left.\mathrm{PPh}_{3} \mathrm{I}_{2}\right)$}

Prepared in a similar way to PS-triphenylphosphine dibromide 82, PS-triphenylphoshine diiodide ${ }^{31} \mathbf{8 3}$ (Scheme 11) has been used to convert alcohols to iodides. The utility of this reagent was demonstrated by converting $N$-protected amino alcohols of the type $\mathbf{9 8}$ to the enantiopure $N$-protected $\beta$-amino iodides $\mathbf{9 9}$ and $\mathbf{1 0 0}$. These iodides were then transformed to the $N$ - or $C$-protected homo- $\beta$-amino acids via an overall one carbon homologation procedure. The key step in this process is the synthesis of the enantiopure $N$-protected $\beta$-amino iodides 99 and 100. The process is high yielding, quick, clean and amenable to scale up.

\subsubsection{PS-Phosphonium salts and PS-phosphoranes}

The Wittig reaction is widely used for the introduction of a carbon-carbon double bond. Ford and Bernard ${ }^{32}$ have prepared the polymer supported reagents $(\mathbf{1 0 4}, \mathbf{1 0 5})$. By heating PS-triphenylphosphine 1 with benzyl bromide or methyl iodide in dimethylformamide at $70{ }^{\circ} \mathrm{C}$ over $48 \mathrm{~h}$ to give the phosphonium salts $\mathbf{1 0 2}$ and $\mathbf{1 0 3}$ (Scheme 12) in good yields (86\% and $96 \%$ respectively). The phosphorane $\mathbf{1 0 4}$ was generated by treating $\mathbf{1 0 2}$ with sodium

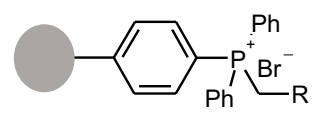

$102 \mathrm{R}=\mathrm{Ph}$

$103 \mathrm{R}=\mathrm{Me}$

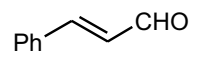

50<smiles>O=C(c1ccccc1)c1ccccc1</smiles>

107

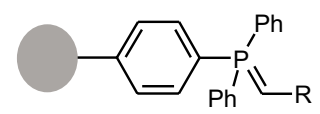

$104 \mathrm{R}=\mathrm{Ph}$

$105 \mathrm{R}=\mathrm{Me}$

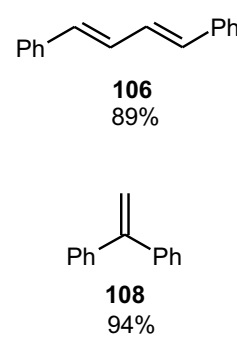

Scheme 12

methoxide and for $\mathbf{1 0 5}$ using the sodium salt of dimethyl sulfoxide. The Wittig reactions proceeded smoothly using tetrahydrofuran and were complete within $16 \mathrm{~h}$ at $20^{\circ} \mathrm{C}$ in very good yields. The chief drawback seems to be that the conditions required for the synthesis of the polymer supported Wittig reagents are dependent upon the halide being used and requires some investment of time to optimise the reaction. This inconvenience may deter some chemists, however once made the products from the Wittig reactions can be obtained in high yields as seen in $\mathbf{1 0 6}$ and 108. The yields compare well with the analogous reactions using soluble reagent. Furthermore the polymer supported byproduct, the phosphine oxide, was reduced with trichlorosilane to regenerate PS-triphenylphosphine 1. This was used for further Wittig reactions with no loss in yield.

PS-Wittig reagents have also been used to synthesise retenoid compounds; ${ }^{33}$ these light, moisture and heat sensitive compounds benefit in yield from the minimal workup required using the polymer supported reagents.

\section{$5 \quad$ Supported nucleophiles}

\subsection{PS-Azide}

Nucleophilic substitution by an azide anion is a well documented route into alkyl azides. Some of the problems associated with this reaction are due to the low solubility of inorganic azides in organic solvents. This has been addressed by using organic azides such as tetraalkyl ammonium azide; other methods use phase transfer conditions and in some circumstances Lewis acid catalysis. Usually heating of these thermally instable compounds is required. Azide anion, supported on Amberlite anion exchange resin $\mathbf{1 0 9}$ has been used to substitute activated and non activated alkyl halides at room temperature in quantitative yields (Scheme 13). The resin, PS-azide ${ }^{34} \mathbf{1 0 9}$ was prepared by mixing Amberlite ion exchange resin (chloride form) with an aqueous solution of sodium azide (20\%). The substitution reactions were carried out in a variety of 


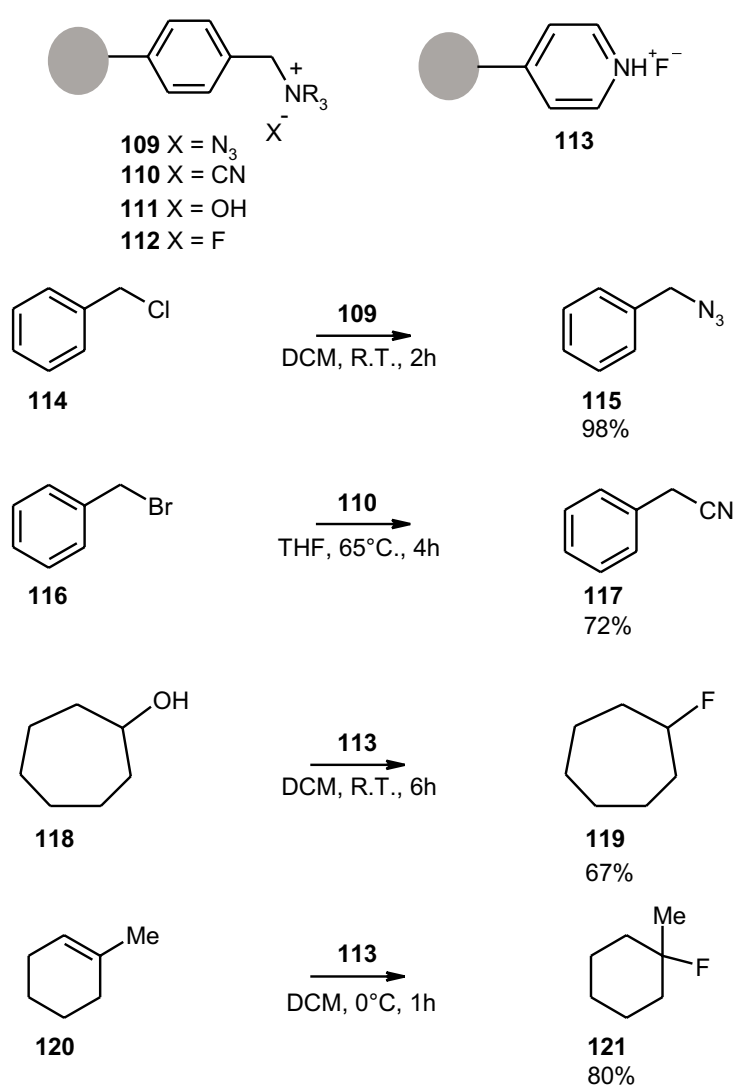

Scheme 13

solvents at $20^{\circ} \mathrm{C}$ but worked best in acetonitrile or dichloromethane, giving the azide products in high yields - as confirmed by the transformation of chloromethylbenzene $\mathbf{1 1 4}$ to azidomethylbenzene $\mathbf{1 1 5}$ (98\%) in dichloromethane at room temperature in $2 \mathrm{~h}$.

\subsection{PS-Cyanide}

Cyanide anion supported on Amberlite anion exchange resin (chloride form) $\mathbf{1 1 0}$ has been prepared ${ }^{35}$ in a similar way to PS-azide 109 (Section 5.1). Many activated halides have been transformed ${ }^{36}$ into the corresponding nitriles in ethanol at $65^{\circ} \mathrm{C}$ within $1.5-3 \mathrm{~h}$. The yields obtained were in the range $43-98 \%$ and were in accord with the reactivity of the halide precursor.

\subsection{PS-Fluoride}

Amberlyst A-26 anion exchange resin (hydroxide form) 111 can be converted to the fluoride form ${ }^{37} 112$ by treatment with dilute aqueous hydrogen fluoride. Organic chlorides, bromides, iodides and methanesulfonates have been transformed into the corresponding fluoride by refluxing the mixture in hexane. Good yields are obtained starting from primary halides, whereas for the secondary halides the elimination pathway predominates giving the olefinic compound. This can be suppressed by synthesising the appropriate methane sulfonate derivative as these are less prone towards elimination.
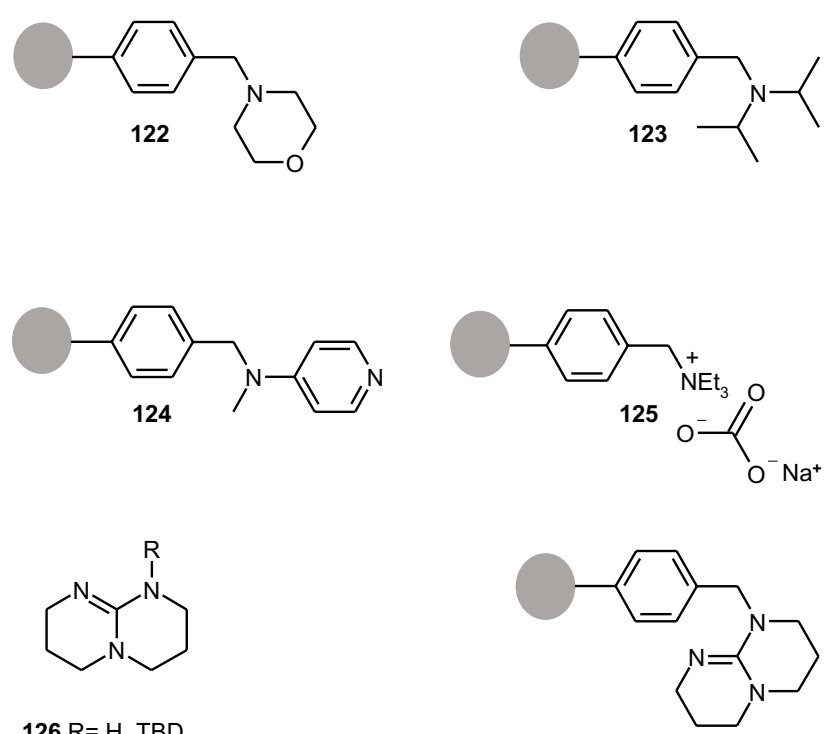

$126 \mathrm{R}=\mathrm{H}, \mathrm{TBD}$

$127 \mathrm{R}=\mathrm{Me}, \mathrm{MTBD}$

128
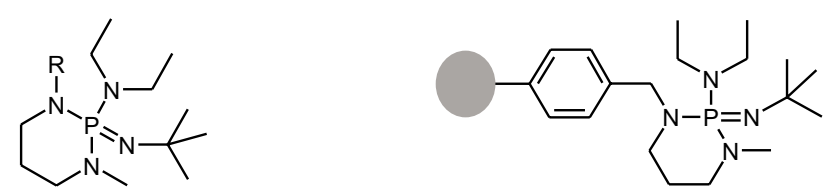

$129 \mathrm{R}=\mathrm{Me}, \mathrm{BEMP}$

130

Scheme 14

Olah has reported ${ }^{38}$ the preparation of poly-4-vinylpyridinium poly(hydrogen fluoride) 113 (Scheme 13) from commercially available cross-linked poly-4-vinylpyridine and anhydrous hydrogen fluoride. The orange / brown coloured polymer fumes when exposed to air but when dispersed in an organic solvent it provides an anhydrous source of hydrogen fluoride. It has been used to convert a range of alcohols to the fluorides under mild conditions and with good yields. In this way cycloheptanol 118 was converted to fluorocycloheptane $\mathbf{1 1 9}$ in dichloromethane at room temperature over $6 \mathrm{~h}(67 \%)$. Alkenes and alkynes can be hydrofluorinated: 1-methylcyclohexene $\mathbf{1 2 0}$ was converted to 1-fluoro-1-methylcyclohexane $\mathbf{1 2 1}$ in dichloromethane at $0{ }^{\circ} \mathrm{C}$ within $1 \mathrm{~h}(80 \%)$. When alkenes are treated in the presence of $N$-bromosuccinimide then the corresponding vicinal bromofluoroalkanes are obtained in good yields.

\section{$6 \quad$ Supported bases}

The polymer supported versions of the commonly used bases such as $N$-methylmorpholine 122, diisopropylethylamine 123, dimethylaminopyridine $\mathbf{1 2 4}$, carbonate $\mathbf{1 2 5}$ (Scheme 14) and hydroxide 111 (Scheme 13) are commercially available and can be substituted for the soluble type with little or no effect on the reaction kinetics. Ganesan $^{39}$ has used Amberlyst A-26 (hydroxide form) 111 to mediate a Dieckmann cyclisation in the synthesis 


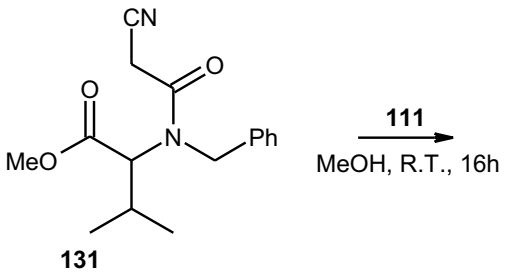<smiles>CC(C)C1C(O)=C(C#N)C(=O)N1Cc1ccccc1</smiles><smiles>COc1cccc(O)c1</smiles>
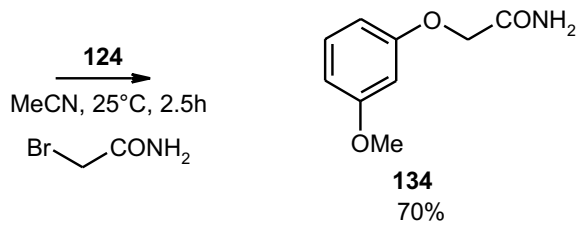<smiles>O=C1CSC(=O)N1</smiles><smiles>Cc1ccc(C(=O)C[C@H](C(=O)CBr)N(C)C)cc1</smiles><smiles>Cc1ccc(C(=O)CN2C(=O)CSC2=O)cc1</smiles><smiles>Cc1cc2ccccc2[nH]1</smiles>

$$
\begin{aligned}
& \stackrel{130}{\mathrm{MeCN}, 25^{\circ} \mathrm{C}, 2.5 \mathrm{~h}} \\
& \mathrm{Br} \longrightarrow \mathrm{CO}_{2} \mathrm{Et}
\end{aligned}
$$

Scheme 15 co-workers. ${ }^{41}$ A hydroxyphenyl porphyrin was attached to solid-phase via the hydroxyl group and after some synthetic manipulation was cleaved from resin to reveal the hydroxy group. This was then $O$-alkylated using PS-TBD 128, showing a good use of solid-phase chemistry and solution-phase chemistry using supported reagents. PSTBD 128 has also been shown to be effective in mediating the $\mathrm{N}$-alkylation of the sulfimide $\mathbf{1 3 5}$ to the product $\mathbf{1 3 6}$ in an agreeable yield $(65 \%)$. In a later publication the same workers report the use of the organic super base 2-tert-butylimino-2-diethylamino-1,3-dimethylperhydro-1,3,2-diazaphosphorine (BEMP) $\mathbf{1 2 9}$ as the polymer supported variation $^{42}$ (PS-BEMP) 130; to $N$-alkylate weakly acidic heterocycles such as the indole $\mathbf{1 3 7}$ in acetonitrile at $25^{\circ} \mathrm{C}$ over 2.5 h providing the derivative 138 (94\%).

\section{$7 \quad$ Supported coupling reagents}
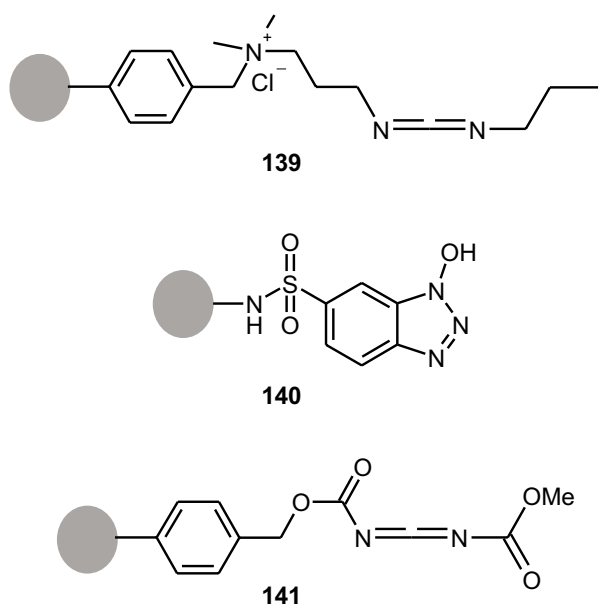

Scheme 16

The value of the carbodiimide coupling reagents such as diisopropylcarbodiimide (DIC) in forming amide or ester bonds is evident from their widespread usage. Their use is sometimes complicated by difficulty in separating the desired product from the $N, N^{\prime}$-dialkylurea co-product. This has in part been addressed by the development of 1-ethyl3-(3-dimethylaminopropyl)carbodiimide (EDC) which provides a basic handle allowing for the removal of urea and $\mathrm{N}$-acyl urea byproducts if any, by extraction into an aqueous acidic phase. Polymer supported versions of these reagents (PS-DIC ${ }^{8} 11$ and PS-EDC ${ }^{43} 139$ ) have been synthesised. They can be used, if required to produce amides or esters under anhydrous conditions. This, combined with the benefit of a simple workup makes them particularly effective for small scale syntheses such as for Mosher's amides ${ }^{44} /$ esters or library synthesis. Monsanto have prepared a library of benzoxazinones ${ }^{45}$ using PSEDC 139 a representative example is seen in Scheme 17. The anthranilic acid derivative $\mathbf{1 4 2}$ was treated with PSEDC 139 in dimethylformamide at room temperature for 
$12 \mathrm{~h}$ and the cyclo-dehydration which resulted produced the benzoxazinone 143 in a good yield (75\%), because uncyclised material remained on the solid support, the product $\mathbf{1 4 3}$ was of high purity (99\%). Polymer supported 1hydroxybenzotriazole ${ }^{46}$ (HOBt) 140 has been used in combination with coupling reagents such as bromo-trispyrrolidinophosphonium hexafluorophosphate (PyBroP). Reaction of these with carboxylic acids generate support bound active esters. These can be treated with a variety of primary and secondary amines to afford the corresponding amide. In this way 3-chlorobenzoic acid 144 was treated with PS-HOBT 140 in the presence of bromo-trispyrrolidinophosphonium hexafluorophosphate (PyBroP) in dimethylformamide at room temperature over $3 \mathrm{~h}$ to give the active ester 145 . Subsequent reaction with benzylamine 146 in dimethylformamide at room temperature over $20 \mathrm{~h}$ gave the amide $\mathbf{1 4 7}$ in a good yield (85\%). Polymer supported azodicarboxylate ${ }^{47} 141$ (PS-DEAD), in conjunction with triphenylphosphine, serves to activate a wide range of oxygen functions in the Mitsunobu reaction. It functions well and gives yields comparable to the soluble dialkyl azodicarboxylates. Ethyl cyanoethanoate 148 has been reacted with PS-DEAD 141 and propanol in tetrahydrofuran under Mitsunobu conditions to give the $C$-alkylated product $\mathbf{1 5 0}$ in moderate yield $(42 \%)$ over 24h. PS-DEAD 141 shows no tendency to detonate and can be recycled up to five times without loss in activity.
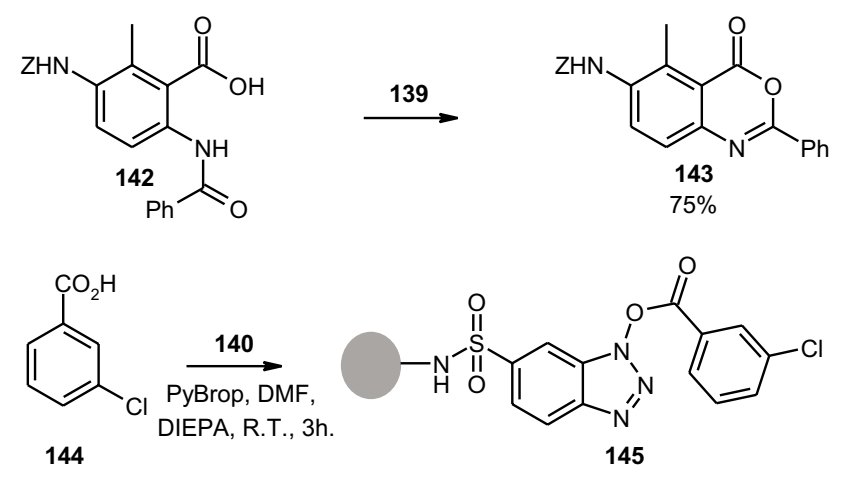

144<smiles>NCc1ccccc1</smiles>

146

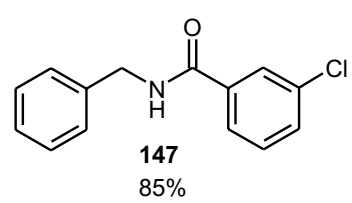

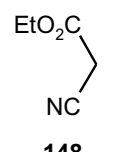

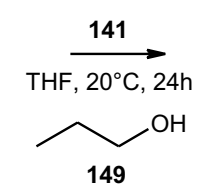

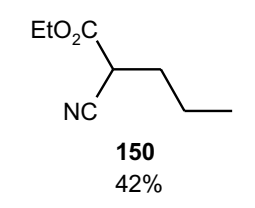

Scheme 17
8

Supported catalysts

The generation of hybrid catalysts which combine the attributes of homogeneous catalysts with the experimental ease of heterogeneous catalysts has lured many workers into this area of research. The promise of simple recovery and re-usability is usually hampered by the more difficult synthesis and characterisation of the support bound catalyst. The solid-support also leads to a perturbation of the function of the catalyst.

The catalytic system devised by Sharpless for the asymmetric dihydroxylation ${ }^{48}$ of olefins using the cinchona alkaloids was heralded as a landmark achievement. Not surprisingly polymer supported versions have also been reported. In a quest to ease the recovery of the ligands after the reaction is complete, the use of PS-cinchona alkaloids has been studied. These suffer from the disadvantages of longer reaction times and lower enantioselectivity. This has led to the recent introduction of PEG-supported alkaloids ${ }^{49}$ which give similar reactivity and enantioselectivity to the original Sharpless system. Bolm and co-workers have reported asymmetric dihydroxylation with silica anchored alkaloids. ${ }^{50} \mathrm{~A}$ modified dihydroquinidine - diphenylpyrazinopyridazine [(DHQD $)_{2}$-DPP] based ligand was synthesised and attached to commercially available chloropropyl functionalised silica via an ether linkage (ester and amide linkages were also evaluated) to give the solid-supported catalyst 151. Using 151, styrene 154 was subjected to the standard dihydroxylation conditions (Scheme 18) in tert-butyl alcohol - water mixture $(1: 1 \mathrm{v} / \mathrm{v})$ with potassium ferricyanide - potassium carbonate as co-oxidant and $2 \mathrm{~mol} \%$ of immobilised ligand with $0.5-1 \mathrm{~mol} \%$ of potassium osmate(VI) dihydrate. 155 was obtained in high yield (93\%) and enantioselectivitiy (98\%ee). The SS-alkaloids were recovered quantitatively and the recycled catalysts used several times without any detectable loss in function. However, osmium metal leaching was observed, thus it was necessary to add small quantities of osmium after each run to maintain catalyst turn-over. This methodology was also used to anchor the modified bis-cinchona alkaloid ligands using a pyrimidine spacer [(DHQD $\left.)_{2}-\mathrm{PYR}\right]$.

The success of asymmetric hydrogenations using the bis(diphenylphosphino)-1,1'-binapthyl (BINAP) ligand / transition metal complexes is measured by their widespread usage in both academic and industrial environments. The expense of the BINAP ligand and the associated problems of transition metal leaching in to the products have led to the synthesis of a PS-BINAP ${ }^{51} \mathbf{1 5 3}$. Modifications were made to the BINAP ligand allowing it to be attached to polymer via an amide linkage. This was then complexed with bis(2-methylallyl)cycloocta-1,5-dieneruthenium(II) in acetone and methanolic hydrogen bromide to provide the active catalyst. This pseudo- $C_{2}-$ symmetric catalyst showed high activity (Scheme 18) and although reaction times were extended the yields and enantiomeric excesses remained comparable to the original homogenous reaction. Using PS-BINAP 153 and the 
<smiles>CCC1CN2CCC1CC2[C@H](O)c1ccnc2ccc(OC)cc12</smiles><smiles>O=C(CCCc1ccc2c(-c3c(-c4ccccc4)ccc4ccccc34)c(-c3ccccc3)ccc2c1)NCC1CCCCC1</smiles><smiles>C=Cc1ccc[13c]c1</smiles>

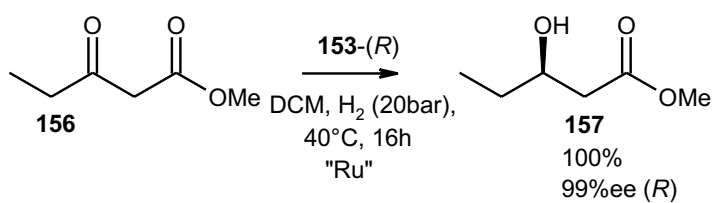<smiles>C=C(NC(C)=O)C(=O)O</smiles>

Scheme 18

conditions outlined in Scheme 18, the keto group of 3oxo-pentanoic acid methyl ester 156 was reduced to give the $\beta$-hydroxy ester 157 in quantitative yield and high enantioselectivity (99\%). Similarly 2 -acetylamino-acrylic acid 158 was reduced to the product 2-acetylamino-propionic acid 159 in $70 \%$ yield and with $75 \%$ enantiomeric excess. The recovered catalyst was re-used and showed only a small loss in turnover. Leaching of ruthenium was measured using inductively coupled plasma atomic emission spectroscopy (ICP-AES) and confirmed that the products contained less than $1 \mathrm{~mol} \%$ of ruthenium.<smiles>COc1ccc(CO)cc1OC</smiles><smiles>COc1cc2c(cc1OC)C1(C=CC(=O)C=C1)CCN(C(=O)C(F)(F)F)C2</smiles><smiles>COc1cc2c(cc1OC)C13CCN(C2)CC1(C)C3</smiles>

$2 \int \underset{\mathrm{MeOH}}{\mathrm{CuSO}_{4} \text { or } \mathrm{NiCl}_{2}}$

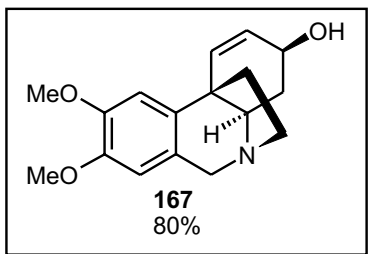

Scheme 19

\section{$9 \quad$ Multi-step synthesis using supported reagents}

In recent years a number of publications have appeared from research groups describing multi-step syntheses using supported reagents and scavenger resins without the need for chromatographic purification of the intermediates at all. The development of these multi-step methods using supported reagents has been best exemplified in the six and ten step linear syntheses of the natural products ( \pm )-epimartidine ${ }^{52} 167$ (Scheme 19 ) and ( \pm )-epibatidine. ${ }^{53}$ The synthesis of $( \pm)$-epimartidine 167 will serve to spotlight this initiative. 
Starting with a PS-perruthenate $\mathbf{1 4}$ mediated oxidation of 3,4-dimethoxybenzyl alcohol $\mathbf{1 6 0}$ in dichloromethane, using the conditions already described (Section 2.1.2) the aldehyde 161 was produced in quantitative yield. This was then reacted with the primary amine $\mathbf{1 6 2}$ to form the corresponding imine which was reduced using PS-borohydride exchange resin $\mathbf{2}$, to give the secondary amine $\mathbf{1 6 3}$ in $90 \%$ yield. The trifluoroacetamide $\mathbf{1 6 4}$ was formed in near quantitative yield (99\%) using trifluoroacetic anhydride and a PS-dimethylaminopyridine 124 equivalent. In the next step the intramolecular phenolic oxidative cyclisation was best achieved using PS-diacetoxyiodobenzene $\mathbf{2 3}$ in trifluoroethanol to give the desired para-para ${ }^{\prime}$ coupled product $165(70 \%)$. In the next step, PS-carbonate 125 was used to effect the intramolecular 1,4-addition to give $\mathbf{1 6 6}$ quantitatively. Finally, the keto group of $\mathbf{1 6 6}$ was reduced with PS-borohydride exchange resin 2 in methanol using either nickel chloride hexahydrate or copper sulfate pentahydrate additives. Thus completing the synthesis of ( \pm )-epimartidine 167 without any chromatography.

\section{Conclusions and outlook}

Supported reagents simplify the workup of a reaction, allowing the immobilised reagent or reagents to be easily removed from the reaction mixture using filtration. Within our medicinal chemistry department, chemists are using supported reagents in an effort to reduce the time spent synthesising molecules. Often this acceptance of an unfamiliar technique has been driven by the pressure to decrease the time taken to find new drug candidates. Reports of new supported reagents, coupled with innovative applications within synthesis and much improved commercial availability should help to ensure an increase in their usage. We hope this article will help to dispel some of the confusion experienced by our colleagues planning syntheses using supported reagents.

\section{Suppliers}

In addition to the well known chemical suppliers, the companies listed below sell many of the supported reagents mentioned in the text.

Argonaut Technologies http://www.argotech.com/

Argonaut Technologies U.S. 887 Industrial Road,

Suite G, San Carlos CA 94070. USA.

Tel. +1 888 5981350; Fax +1 6505981359 ,

E-mail: info@argotech.com

Calbiochem-Novabiochem

http://www.nova.ch/

Boulevard Industrial Park, Padge Road, Beeston,

Nottingham NG9 2JR. UK.

Tel. +44 (0)115 9430840; Fax +44 (0)115 9430951,

E-mail: uk@nova.ch
Polyphor Ltd

http://www.polyphor.com/

Winterthurerstrasse 190, CH-8057 Zürich, Switzerland

Tel. +41 135046 46; Fax +41 13504645

E-mail: contact@polyphor.com

\section{Acknowledgement}

We express our thanks to our colleagues Dr Robin Fairhurst, Dr Thomas Keller, Dr Clive McCarthy and Dr Keith Menear for their useful comments.

\section{References and Notes}

(1) Bhalay, G. Chem. Br. 1999, 35, 25-29. Brown, A. R.; Hermkens, P. H. H.; Ottenheijm, C. J.; Rees, D. C. Synlett 1998, 817.

(2) Hodges, J. C. Synlett 1999, 152.

(3) Allin, S. M.; Nasturicia, D.; Shuttleworth, S. J.; Wilson, R. D. Synthesis 2000, 1035. Thompson, L. A. Curr. Opin. Chem. Biol. 2000, 324. Obrecht, D.; Villalgordo, J. M. SolidSupported Combinatorial and Parallel Synthesis of SmallMolecular-Weight Compound Libraries; Pergamon: Oxford, 1998. Maud, J. M. In Solid Supports and Catalysts in Organic Synthesis; Smith, K., Ed.; Ellis Horwood PTR Prentice Hall: London, 1992; p 40.

(4) Ashok, S. K.; Omura, K.; Swern, D. J. Org. Chem. 1976, 41, 957.

(5) Liu, Y.; Vederas, J. C. J. Org. Chem. 1996, 61, 7856.

(6) Andrews, M. D.; Chai, S.; Harris, J. M.; Liu, Y.; Vederas, J. C. J. Org. Chem. 1998, 63, 2407.

(7) Moffatt, J. G. J. Org. Chem. 1971, 36, 1909.

(8) Shen, C-M.; Weinshenker, N. M. Tetrahedron Lett. 1972 , 3281. Shen, C-M.; Weinshenker, N. M. Tetrahedron Lett. 1972, 3285.

(9) Hinzen, B.; Ley, S. V. J. Chem. Soc., Perkin Trans. 1 1997, 1907.

(10) Hinzen, B.; Lenz, R.; Ley, S. V. Synthesis 1998, 977.

(11) Hinzen, B.; Ley, S. V. J. Chem. Soc., Perkin Trans. 1 1998, 1.

(12) Nogami, G.; Togo, H.; Yokoyama, M. Synlett 1998, 534.

(13) Finch, H.; Ley, S. V.; Thomas, A. W. J. Chem. Soc., Perkin Trans. 1 1999, 669.

(14) Kolb, H. C.; Sharpless, K. B.; VanNieuwenhze, M. S. Chem Rev. 1994, 94, 2483. Lohray, B. B. Tetrahedron: Asymmetry 1992, 3, 1314.

(15) Cainelli, G.; Contento, M.; Manescalchi, F.; Plessi, L. Synthesis 1989, 45.

(16) Endo, M.; Kobayashi, S.; Nagayama, S. J. Org. Chem. 1998, 63, 6094.

(17) Shing, T. K. M.; Zhong, Y-L. J. Org. Chem. 1997, 62, 2622.

(18) Bailey, F. C.; Gibson, H. W. J. Chem. Soc., Chem. Commun. 1977, 22, 815. Gyoung, Y. S.; Park, K. B.; Yoon, N. M. Tetrahedron Lett. 1983, 5367. Jagadale, M. H.; Mane, R. B.; Salunkhe, M. M.; Sande, A. R. Tetrahedron Lett. 1984, 3501.

(19) Hutchins, R. O.; Natale, N. R.; Taffer, I. M. J. Chem. Soc., Chem. Commun. 1978, 24, 1088.

(20) Choi, J.; Yoon, N. M. Synlett 1993, 135. Choi, J.; Lee, H. J.; Yoon, N. M. Bull. Korean Chem. Soc. 1993, 14, 543. Bandgar, B. P.; Nikat, S. M.; Wadgaonkar, P. P. Synth. Commun. 1995, $25,863$.

(21) Murphy, F.; Nicolaou, K. C.; Pastor, Pastor, J.; Winssinger, N. Angew. Chem. Int. Ed. 1998, 37, 2534.

(22) Gerigk, U.; Gerlach, M.; Neumann, W. P.; Vieler, R.; Weintritt, V. Synthesis 1990, 448.

(23) Gerlach, M.; Jördens, F.; Kuhn, H.; Neumann, W. P.; Peterseim, M. J. Org. Chem. 1991, 21, 5971 
(24) Gibson, R. H.; Kroll, L. C. J. Am. Chem. Soc. 1971, 73, 3062. Farall, M. J.; Frechet, M. J. J. Org. Chem. 1976, 41, 3877.

(25) Hodge, P.; Richardson, G. J. Chem. Soc., Chem. Commun. $\mathbf{1 9 7 5}, 15,622$.

(26) Brinkman, H. R.; Landi, Jr., J. J. Synthesis 1992, 1093. Caputo, R.; Cassano, E.; Longobardo, L.; Mastroianni, D.; Palumbo, G. Synthesis 1995, 141.

(27) Harrison, C. R.; Hodge, P.; Rogers, W. J. Synthesis 1977, 41.

(28) Relles, H. M.; Schluenz, R. W. J. Am. Chem. Soc. 1974, 96, 6469.

(29) Mestres, R.; Palomo, C. Synthesis 1981, 373.

(30) Akelah, A.; El-Borai, M. Polymer 1980, 21, 255.

(31) Caputo, R.; Cassano, E.; Longobardo, L.; Palumbo, G. Tetrahedron 1995, 12337.

(32) Bernard, M.; Ford, W. T. J. Org. Chem. 1983, 48, 326.

(33) Bernard, M.; Ford, W. T.; Nelson, E. C. J. Org. Chem. 1983, $48,3164$.

(34) Hassner, A.; Stern, M. Angew. Chem. Int. Ed. Engl. 1986, 25, 478.

(35) Castells, J.; Dunach, E. Chem. Lett. 1984, 1859.

(36) Gordon, M.; DePamphyilis, M. L.; Griffin, C. E. J. Org. Chem. 1963, 28, 698.

(37) Cainelli, G.; Manescalchi, F.; Synthesis 1976, 472.

(38) Li, X-Y.; Olah, G. A. Synlett 1990, 267.

(39) Ganesan, A.; Kulkarni, B. A. Angew. Chem. Int. Ed. Engl. 1997, 36, 2454

(40) Mohan, R.; Morrissey, M. M.; Xu, W. Tetrahedron Lett. 1997, 7337.

(41) Boyle, R. W.; Elgie, K. J.; Scobie, M. Tetrahedron Lett. 2000 , 2753.
(42) Mohan, R.; Morrissey, M. M.; Xu, W. Bioorg. Med. Chem. Lett. 1998, 8, 1089.

(43) Desai, M. C.; M, L.; Stramiello, S. Tetrahedron Lett. 1993, 7685.

(44) Adamczyk, M.; Fishpaugh, J. R. Tetrahedron Lett. 1996, 7171.

(45) Buckman, B. O.; Mohan, R.; Morrissey, M. M.; Tetrahedron Lett. 1998, 1487. Flynn, D. L.; Parlow, J. J. Tetrahedron 1998, 4013.

(46) Déprez, B. P.; Pop, I. E.; Tartar, A. L. J. Org. Chem. 1997, 62, 2594. Dendrinos, K.; Huang, W.; Jeong, J.; Kalivretenos, A. G. Chem. Commun. 1998, 499.

(47) Arnold, L. D.; Assil, H. I.; Vederas, J. C. J. Am. Chem. Soc. 1989, 111, 3973.

(48) Kolb, H. C.; Sharpless, K. B.; VanNieuwenhze, S. Chem. Rev. 1994, 94, 2483.

(49) Han, H.; Janda, K. D. J. Am. Chem. Soc. 1996, 118, 7632. Bolm, C.; Gerlach, A. Angew. Chem. Int. Ed. Engl. 1997, 36, 741.

(50) Bolm, C.; Gerlach, A.; Maischak, A. Chem. Commun. 1997, 2353.

(51) Ashton, M. R.; Baxter, A. D.; Bayston, D.; Fraser, J. L.; Moses, E.; Polywka, M. E. C. J. Org. Chem. 1998, 63, 3137.

(52) Ley, S. V.; Murray, P. J.; Thomas, A. W.; Schucht, O. J. Chem. Soc., Perkin Trans. 1 1999, 1251.

(53) Habermann, J.; Ley, S. V.; Scott, J. S. J. Chem. Soc., Perkin Trans. 1 1999, 1253.

Article Identifier:

1437-2096,E;2000,0,12,1846,1859,ftx,en;T01300ST.pdf 